\title{
Insights on the impact of telecommunication companies on the environment
}

\author{
Ioana-Miruna TĂTARU \\ University POLITEHNICA of Bucharest, Romania \\ tataru.miruna@gmail.com \\ Elena FLEACĂ \\ University POLITEHNICA of Bucharest, Romania \\ elena.fleaca@upb.ro \\ Bogdan FLEAC $\breve{A}$ \\ University POLITEHNICA of Bucharest, Romania \\ bogdan.fleaca@upb.ro
}

\begin{abstract}
To perform their business operations, telecommunication companies need to consume energy. This paper aims to analyze and compare the energy consumption and their greenhouse gas emissions for there of the biggest telecommunication companies: Vodafone, Orange and Telekom. Although the scientific literature proposed some analysis on the environmental measures that the telecommunication companies have to take, there is a shortage of researchers focused on GRI reporting data and the pairwise comparison method. The authors compared these telecommunication companies' emissions under the following criteria: energy consumption (GRI 302-1), scope 1 (GRI 305-1), scope 2 (GRI 305-2) and scope 3 (GRI 305-3) greenhouse gas emissions, reduction of emissions (GRI 305-5), using the pairwise comparison method. To reduce their emissions, companies developed a sustainability strategy. This paper will further emphasize what are the plans to reduce emissions for the company which, following the analysis, pollutes the most. To provide an overview of the future of the company which, by the analysis, pollutes the most, the authors have identified and analyzed what are the main actions that the company should take to reduce their impact on the environment. To do so, the authors firstly analyze the causes of the pollution produced by the telecommunication company using Ishikawa diagram. Then, it identifies what are the main organizational processes that can be improved using APQC standardization, to show that the improvement can be made if the organization adjusts their organizational processes. This paper is an enhancement to the studies form the field because it provides a comparative analysis on three of the most competitive telecommunication companies in the world, uses GRI criteria and pairwise comparison method and gives an overview on the next steps for the telecommunication company to reduce their greenhouse gas emissions.
\end{abstract}

Keywords: sustainability, telecommunication, environment, greenhouse gases, energy.

\section{Introduction}

Telecommunication companies have a direct impact on the environment on which they perform their operations. Their impact is on the social field, because they contribute as employers through the jobs available to the community. Their impact is also on the economic field, because they provide telecommunication services and products, television, telephone and Internet.

The most significant impact of the telecommunication companies is on the environmental field. They contribute directly and indirectly to the environment, through greenhouse gases (GHGs), because they have a significant use of energy and therefore, they are a source of these emissions. The studies show that by 2030 , telecommunications companies will be responsible for 
$2 \%$ of the global GHG emissions, similar to the aviation industry (Vodafone Sustainable Business Report 2018, 2018).

Therefore, there is an increasing need to inform and analyze telecommunication companies' contribution towards reducing the GHG emissions and protecting the environment.

The aim of this paper is firstly to analyze the impact of the telecommunication companies on the environment. To do this, the GHG emissions reported by three major telecommunication companies will be analyzed and compared using the pairwise comparison method and GRI ecological disclosures: 302-1, 305-1, 305-2, 305-3 and 305-5.

The next section comprises a contribution towards the prospects for the future and what are the actions that companies can undertake in order to create more sustainable business processes. To perform this, the first step is to analyze the causes of the pollution. The main causes of the pollution are identified using an Ishikawa diagram. Then, the main organizational processes that can contribute towards the environment are analyzed, using APQC standardization for the telecommunication industry.

\section{Literature review}

A recent study shows that, telecommunication companies must respect the regulations imposed by the government related to the GHG emissions limit (Sutherland, 2016). Therefore, it is not only a need for the companies to reduce their GHG emissions in order to benefit the environment, but it is also a requirement imposed by law.

Telecommunication companies need to take measures to keep their GHG at the limit and also to reduce them. Their contribution towards GHG emissions can be reduced by using their capabilities and knowledge in the environmental field. These companies have the resources to create sustainable solutions (Domazet et al., 2018; Paunescu, et al., 2018). Examples of solutions in this domain created by telecommunication companies are those described in the Vodafone Group CSR report. The telecommunication company predicts that by 2030, Internet of Things solutions would help reducing by $20 \%$ the total global greenhouse emissions. These solutions help the organizations by becoming sustainable because they provide remote conferencing, smart street lighting, smart metering and smart logistics (Vodafone Sustainable Business Report 2018, 2018).

Another study introduced the concept of Green Energy Technology (GET), which comprises a list of initiatives that the telecommunication companies can undertake in order to get an environmentally responsible and cost-effective electricity. The authors indicated solutions related to the use of the renewable energy such as: solar, wind and geothermal power, the creation of "green" office buildings and the use of bio-fuels, presenting also the requirements and the impediments for implementing such solutions (Sivarajan et al., 2019). The concept is also presented as the "green integration" strategy and it comprises measures that telecommunication companies can undertake to reduce the global warming (Ikebe et al., 2007).

This paper is an enhancement to the existing ones in the sustainable telecommunication services domain. It recognizes the regulations imposed by the government and the standards available in the domain, such as GRI. It compares using the pairwise comparison method three of the most representative telecommunication companies in Europe and worldwide: Deutsche Telekom, Vodafone Group and Orange Group, providing information on their greenhouse gas emissions and the percentage of their reduction per year.

Moreover, to enhance the study on "green integration" strategy (Sivarajan et al., 2019), this paper provides an analysis on the causes and the solutions that the telecommunication 
company can undertake to become more sustainable. The causes are identified using the Ishikawa diagram (Luca, 2016).

The solutions provided in the paper are seen as improvements on organizational processes, and the paper uses the process classification (PCF) framework provided by APQC for the telecommunication industry (Telecommunications Process Classification Framework, 2017) to present the organizational processes that contribute towards the greenhouse gas emissions.

PICBE | 204

At the moment of the study, there is a gap between the correlations on greenhouse gas emissions, their causes identified using the Ishikawa diagram and the projected improvement on business processes identified using PCF framework.

\section{Methodology}

The Global Reporting Initiative (GRI) is an international organization, which aims to set reporting standards for companies regarding their positive or negative contributions towards sustainability in the following fields: economical, environmental and social. In the environmental domain it comprises the organization's reporting towards the ecosystems, land, air and water, providing disclosures for each. Disclosures are meant to guide the organization to report their impact and they will be used in the pairwise comparative analysis performed for the three telecommunication companies (About GRI, 2017).

The sustainable reporting is not only a need for the organization in order to have a view on their impact on the environment on which they perform their operations, but also a requirement imposed by the European Union for large companies (Non-financial reporting, 2019). Each year, large companies are required to create a non-financial report and $85 \%$ of them are using the GRI standard to create it (Rezaee \& Fogarty, 2019).

This paper uses firstly the GRI environmental disclosures to provide a detailed analysis on how the telecommunication companies contribute towards the environment. This GRI analysis is performed at group level, the input data being the information available in the global sustainability reports of Vodafone Group Plc, Orange Group and Deutsche Telekom (Vodafone Sustainable Business Report 2018, 2018; CSR Orange Environmental 2018, 2018; Deutsche Telekom Corporate Responsibility Report 2018, 2018).

The method used is the pairwise comparison method, a marketing research methodology that implies the comparison of two candidates under an attribute, and candidates' hierarchy. In other words, each candidate is compared with every candidate and the winner is considered that superior one against the attribute. The winner gets one point and if they are both equal, each candidate gets half point. At the end, after all comparisons are performed, the winner is the one who has the most points (The Method of Pairwise Comparisons, 2019).

The attribute against each pairwise comparison is performed are the most significant GRI environmental disclosures: 302-1 (total energy consumption within the organization), 305-1 (direct GHG emissions), 305-2 (indirect GHG emissions), 305-3 (other indirect GHG emissions) and 305-5 (reduction of GHG emissions) (GRI 302: ENERGY 2016 - Global Reporting Initiative, 2016; GRI 305: EMISSIONS 2016 - Global Reporting Initiative, 2016).

The conclusion of the comparison will provide the telecommunication company who pollutes the most and that organization will be used as a reference for business process sustainable improvement in the next analysis performed in the study. The pairwise comparison method results will determine the organization and its sustainability report will be analyzed in order to provide the contributions towards reducing the greenhouse gas emissions. 
Ishikawa method is a quality management tool that identifies the sources of a problem, enabling the organizations to brainstorm solutions. According to the Ishikawa method, there are 5 or 8 causes on each problem, namely: Man, Method, Measurement, Machine, Material (Luca, 2016).

The identified causes represent the input of the next analysis based on the PCF framework provided by APQC. The framework provides the list of the business processes within an organization activating in a specific industry. It enables companies to monitor and compare their business processes performance both internally and externally with other companies activating in the same industry (Telecommunications Process Classification Framework, 2017).

The PCF framework for the telecommunication industry will be used to classify the business processes that contribute towards the environment and provide useful information for the solutions that the telecommunication company can undertake to achieve sustainable development.

\section{Results and discussions Pairwise comparison}

The first step in the current analysis is the identification of the telecommunication company that needs to adopt a more sustainable approach. This study doesn't take into account the dimension of the organization, the number of sites and the presence in different countries. The data used for the present study has been taken from the Vodafone Group Plc, Orange Group and Deutsche Telekom non-financial reports (Vodafone Sustainable Business Report 2018, 2018; CSR Orange Environmental 2018, 2018; Deutsche Telekom Corporate Responsibility Report 2018, 2018) and it is provided in Table 1 .

Table 1. Experimental data for the analysis of the impact of telecommunications companies on the GRI environment area

\begin{tabular}{|l|l|l|l|}
\hline $\begin{array}{l}\text { GRI } \\
\text { Disclosure }\end{array}$ & Telekom & Vodafone & Orange \\
\hline $302-1$ & $9,2 \mathrm{GWh}$ & $\begin{array}{l}6,233 \\
\mathrm{GWh}\end{array}$ & $\begin{array}{l}1,340 \\
\mathrm{GWh}\end{array}$ \\
\hline $305-1$ & $\begin{array}{l}276727 \\
\text { tonnes }\end{array}$ & $\begin{array}{l}380000 \\
\text { tonnes }\end{array}$ & $\begin{array}{l}331461 \\
\text { tonnes }\end{array}$ \\
\hline $305-2$ & $\begin{array}{l}5553984 \\
\text { tonnes }\end{array}$ & $\begin{array}{l}2200000 \\
\text { tonnes }\end{array}$ & $\begin{array}{l}1044144 \\
\text { tonnes }\end{array}$ \\
\hline $305-3$ & $\begin{array}{l}9112000 \\
\text { tonnes }\end{array}$ & $\begin{array}{l}13261000 \\
\text { tonnes }\end{array}$ & $\begin{array}{l}46170 \\
\text { tonnes }\end{array}$ \\
\hline $305-5$ & $\begin{array}{l}573764 \\
\text { tonnes }\end{array}$ & $\begin{array}{l}5,3 \\
\text { million } \\
\text { tonnes }\end{array}$ & $\begin{array}{l}17478 \\
\text { tonnes }\end{array}$ \\
\hline
\end{tabular}

Source: Non-financial reports data (Vodafone Sustainable Business Report 2018, 2018; CSR Orange Environmental 2018, 2018; Deutsche Telekom Corporate Responsibility Report 2018, 2018).

The PCF framework for the telecommunication industry will then be used to classify the processes responsible with the organization's environmental impact.

GRI 302 contains a series of topic-specific disclosures on: energy consumption within and outside the organization, energy intensity, reductions of energy consumption and in energy requirements of products and services (GRI 302: ENERGY 2016 - Global Reporting Initiative, 2016). Pairwise comparison under GRI 302-1 attribute reports that Orange has the lowest energy 
consumption in the organization, followed by Vodafone and then by Telekom, as described in Table 2.

Table 2. Pairwise comparison under GRI 302-1 attribute

\begin{tabular}{|l|l|l|l|l|}
\hline Company & Telekom & Vodafone & Orange & Total \\
\hline Telekom & N/A & 0 & 0 & 0 \\
\hline Vodafone & 1 & N/A & 0 & 1 \\
\hline Orange & 1 & 1 & N/A & 2 \\
\hline
\end{tabular}

PICBE | 206

Source: Authors' own research.

GRI 305-1 indicates that the organization will report information on the direct GHG emissions in metric tons of CO2 (GRI 305: EMISSIONS 2016 - Global Reporting Initiative, 2016). Pairwise comparison under GRI 305-1 attribute reports that Telekom has the lowest direct greenhouse gas emissions, followed by Orange and then Vodafone, as described in Table 3.

Table 3. Pairwise comparison under GRI 305-1 attribute

\begin{tabular}{|l|l|l|l|l|}
\hline Company & Telekom & Vodafone & Orange & Total \\
\hline Telekom & N/A & 1 & 1 & 2 \\
\hline Vodafone & 0 & N/A & 0 & 0 \\
\hline Orange & 0 & 1 & N/A & 1 \\
\hline
\end{tabular}

Source: Authors' own research.

GRI 305-2 indicates that the organization will report information on the indirect GHG emissions in metric tons of CO2 (GRI 305: EMISSIONS 2016 - Global Reporting Initiative, 2016). Pairwise comparison under GRI 305-2 attribute reports that Orange has the lowest indirect greenhouse gas emissions, followed by Telekom and then Vodafone, as described in Table 4.

Table 4. Pairwise comparison under GRI 305-2 attribute

\begin{tabular}{|l|l|l|l|l|}
\hline Company & Telekom & Vodafone & Orange & Total \\
\hline Telekom & N/A & 1 & 0 & 1 \\
\hline Vodafone & 0 & N/A & 0 & 0 \\
\hline Orange & 1 & 1 & N/A & 2 \\
\hline
\end{tabular}

Source: Authors' own research.

GRI 305-3 indicated that the organization will report gross other indirect GHG emissions in metric tons of CO2 (GRI 305: EMISSIONS 2016 - Global Reporting Initiative, 2016). Pairwise comparison under GRI 305-3 attribute reports that Orange has the smallest indirect emissions of other types of greenhouse gases, followed by Telekom and then Vodafone, as described in Table 5.

Table 5. Pairwise comparison under GRI 305-3 attribute

\begin{tabular}{|l|l|l|l|l|}
\hline Company & Telekom & Vodafone & Orange & Total \\
\hline Telekom & N/A & 1 & 0 & 1 \\
\hline Vodafone & 0 & N/A & 0 & 0 \\
\hline Orange & 1 & 1 & N/A & 2 \\
\hline
\end{tabular}

Source: Authors' own research.

GRI 305-5 indicates that the organization will report the amount of GHG emissions reduced as a direct result of initiatives, in metric tons of CO2 (GRI 305: EMISSIONS 2016 - 
Global Reporting Initiative, 2016). Pairwise comparison under GRI 305-5 attribute reports that Orange has the smallest reduction of direct greenhouse gas emissions, followed by Telekom and then Vodafone, as described in the next table.

Table 5. Pairwise comparison under GRI 305-5 attribute

\begin{tabular}{|l|l|l|l|l|}
\hline Company & Telekom & Vodafone & Orange & Total \\
\hline Telekom & N/A & 0 & 1 & 1 \\
\hline Vodafone & 1 & N/A & 1 & 2 \\
\hline Orange & 0 & 0 & N/A & 0 \\
\hline
\end{tabular}

PICBE | 207

Source: Authors' own research.

The results of the pairwise comparison performed on telecommunications companies under GRI ecological area are in Table 6.

Table 6. Pairwise comparison under GRI environmental disclosures

\begin{tabular}{|l|l|l|}
\hline Company & Total & Place \\
\hline Telekom & 5 & II \\
\hline Vodafone & 3 & III \\
\hline Orange & 7 & I \\
\hline
\end{tabular}

Source: Authors' own research.

The current pairwise comparison analysis shows that in terms of the total energy consumption in the organization, direct, indirect and other type emissions of greenhouse gases and reduction of the direct emissions of greenhouse gases, Orange Group is classified the first. The reported emissions related to business travel are also the lowest of the three groups. On the second place is Deutsche Telekom and on third place is Vodafone Group.

Vodafone Group reported the largest reduction in direct greenhouse gas emissions through its environmental programs. However, it is important to mention that the result is not surprising, because it is the company that reported the most greenhouse gas emissions.

However, the current study is limited. Only five GRI environmental disclosures have been taken into consideration. Also, the study doesn't provide delimitation between the companies in terms of the dimension of them, the number of sites and network coverage.

Compared with Deutsche Telekom and Orange Group, Vodafone Group's non-financial report is more detailed and it contains a specific section for the energy innovation. The company is paying a close attention to their environmental footprint and it is investing in solutions to reduce their impact on the society they perform their operations in.

Another source of the result of the analysis is that Vodafone Group is a pioneer in $5 \mathrm{G}$, although the group respects the international regulations set by the International Commission on Non-Ionizing Radiation Protection (ICNIRP) for electromagnetic field (EMF) (Vodafone Sustainable Business Report 2019, 2019).

As the results of this pairwise comparison show, Vodafone Group is also the organization that undertakes the most activities for climate change mitigation, as their sustainability report shows (Vodafone Sustainable Business Report 2019, 2019).

Vodafone Group is paying a close attention to environmental-friendly connectivity and it is the first company who has deployed a Narrowband-IoT solution (a device that provides connectivity between two objects situated in places with no signal or there are too many objects to be economically viable to be connected to a $4 \mathrm{G}$ network). Narrowband-IoT battery lasts 10 
years and it is a tool that can help customers use energy more efficiently by tracking the consumption. (Vodafone Sustainable Business Report 2019, 2019; Vodafone IoT, 2017)

Therefore, a future study should place Vodafone Group in the first place in terms of GHGs emissions, renewable energy and overall environmental footprint.

The next step in this study is to analyze the possible causes of the greenhouse gas emissions for Vodafone Group Plc, the company that according to the pairwise comparison method has the largest greenhouse gas emissions from the three telecommunication companies analyzed, and then to take a closer look at the business processes responsible for them.

\section{Causes identification using Ishikawa method}

Ishikawa method is a powerful cause-effect analysis tool. When designing the Ishikawa diagram, the resources provided in the Vodafone Group Plc non-financial report have been used (Vodafone Sustainable Business Report 2018, 2018; Vodafone Sustainable Business Report 2019, 2019). The Ishikawa diagram aims to identify the five most representative causes for the telecommunication company's impact on the environment as in Figure 1.

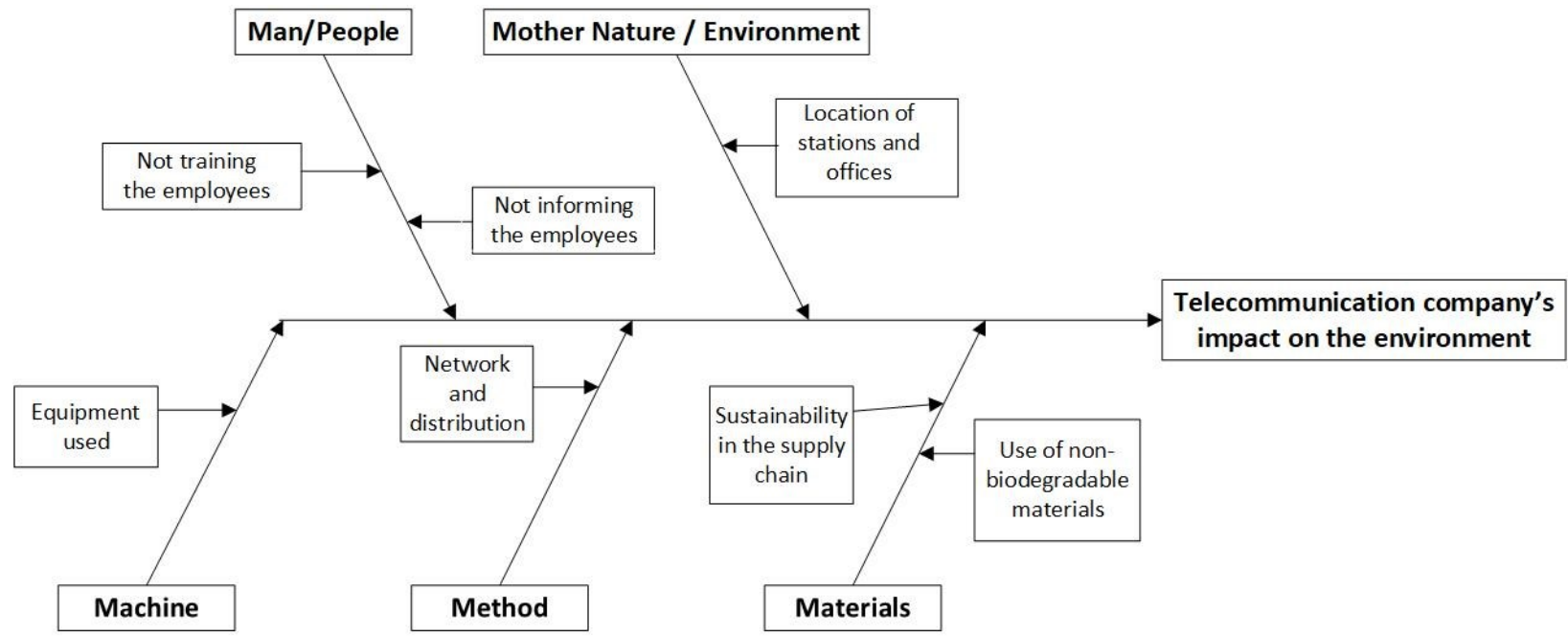

Figure 1. Ishikawa diagram for the telecommunication company's impact on the environment

Source: Authors' own research.

The man cause (Luca, 2016) represents the human resources in the company. The employees are not properly informed and trained to have a sustainable work approach. People are the engine of the organization and without them the business operations cannot be performed. To obtain sustainable processes, employees must be properly trained in the sustainably field. They must adjust their work and the management has to provide support for sustainability. In the proposed solution section, a list of the organizational processes will be presented responsible for training the employees along with the possible methods.

The machine cause (Luca, 2016) represents the equipment used. The real challenge for a telecommunication company is to reduce the total energy consumption in their base stations. Base stations can be equipped with temperature control systems, upgraded power conversion equipment and smart energy-efficient single radio access network equipment (Vodafone Sustainable Business Report 2019, 2019). 
The method cause (Luca, 2016) represents the network and distribution. Telecommunication companies must collaborate with their suppliers who supply, install and maintain their networks and share best practices in terms of environment compliance and risk management.

The materials cause (Luca, 2016) represents the non-biodegradable materials used and the sustainability in the supply chain. Although telecommunication companies cannot influence how cellphones that they sell are produced, they can make sure that the suppliers respect health, safety and sustainability standards. Bio-degradable materials can be used to produce the SIM cards, the cellphones packing and even for the antennas.

The mother nature or the environment cause (Luca, 2016) represents the location of the base stations and the offices. Both offices and base station locations can be controlled.

Telecommunication companies should ensure that the offices in which they perform their business are environmentally-friendly. Although the office can be placed in an already polluted area, companies should take measures to reduce their environment footprint there (Vodafone Sustainable Business Report 2019, 2019).

As causes have been identified, the next step is to take a closer look at the business processes that can be optimized in order to create a more sustainable organization.

\section{Proposed solutions for creating sustainable business processes}

The first step to create sustainable business processes is to identify the processes. The causes identified using Ishikawa method provide an indication of them: man - human resources, machine, materials, mother nature - operating processes, method - management processes.

The APQC's Process Classification Framework (PCF) provides the telecommunication industry's specific processes and activities which contain major process types as operating, management and support.

The operating processes are the development of the organization's strategy, the development of the products and services, the selling of the products and services, the delivery of the products and services and the customer service management.

On the other hand, the operating processes cannot be performed without the support of the management and support processes, such as: human capital management, information technology systems management, financial resources management, property management, environmental health and safety management, external relationships management, knowledge, improvement and change management and network management (Telecommunications Process Classification Framework, 2017). Some of these processes contribute towards the company's environment impact. For example, during the base stations generate greenhouse gas emissions while they operate.

The following APQC processes have been identified to have a direct impact on the organizations' environment footprint.

Any sustainable development strategy starts with the environmental impact assessment process, defined by PCF as manage environmental, health and safety process (Telecommunications Process Classification Framework, 2017). This process starts with the development of a health, safety, and environmental program that is created under the social responsibility department. The program is then implemented and monitored to comply with regulations. The social responsibility department should be supported by the management to implement remediation initiatives, if needed (Telecommunications Process Classification Framework, 2017). 
The telecommunications industry has a direct effect on the environment in which it operates, both ecologically, socially and politically. Therefore, the process of evaluating the impact of operations on the environment is a basic process within the organization and contributes directly to the achievement of the sustainable development objectives. For example, Vodafone Group has a sustainable development strategy that comprises three pillars: women's empowerment, youth skills and jobs, energy innovation (Vodafone Sustainable Business Report 2019, 2019). Each program implemented by the company sustains some of the UN Sustainable Development Goals such as: quality education, gender equality, decent work and economic growth, affordable and clean energy, climate action (Vodafone Sustainable Business Report 2019, 2019; About the Sustainable Development Goals - United Nations Sustainable Development, 2015).

Vodafone Group Plc sets an example on how to project as sustainable development strategy and provides proven programs and initiatives that contribute towards the UN Sustainable Development Goals. Although during the pairwise comparison analysis performed in the previous section, Vodafone Group Plc has reported to be the one that needs the most to implement programs to reduce their environmental footprint, this company is the one that provides the most initiatives and has clear objectives to contribute towards climate action: to buy $100 \%$ of their energy from renewable sources by 2025 and to reduce their greenhouse gas emissions by 50\% (Vodafone Sustainable Business Report 2019, 2019).

Another PCF process that contributes directly towards the organizations' environmental footprint is the properties management. The telecommunications industry has a direct effect on the environment in which it operates through the presence of base stations, equipment, servers, properties, offices. "Develop property strategy and long-term vision" process comprises the alignment of the property requirements with the business strategy, the external environment evaluation and the decision making to build or buy (Telecommunications Process Classification Framework, 2017). In the sustainability context, the process goes beyond the simple build or buys decision and it involves creating sustainable buildings. Solutions imply the use of the renewable energy for offices as much as possible, as presented by (Sivarajan et al., 2019) and the use of Internet of Things solutions for lighting, cooling and heating the building.

A sustainable development strategy cannot be implemented successfully without engaging the employees. Employees, the engine of the company, need to be informed about the ways of adopting responsible social behavior and then apply them in their daily work. PCF names the process as employee engagement on energy innovation (Telecommunications Process Classification Framework, 2017). An employee's engagement program can comprise: newsletters, quizzes on environmental topics, team-buildings for planting trees, a sustainability day in the office. An example of a successful employee engagement program is \#RedLovesGreen implemented by Vodafone Group Plc (Vodafone Sustainable Business Report 2019, 2019). It is a platform containing news, stories, information to engage the employees on environmental issues (Vodafone Sustainable Business Report 2019, 2019). More than 5000 employees have been engaged on the topic and more than 7000 employees have completed an energy awareness elearning module (Vodafone Sustainable Business Report 2019, 2019).

The developed products must be consistent with both the business strategy and the sustainable development strategy of the telecommunication company. The PCF process responsible with this is the development and management of the products and services process category. A complex process category that comprises a group of processes, processes and their activities. Telecommunication companies have the knowledge to develop sustainable products 
and services, such as Internet of Things solutions. Vodafone Group Plc has reported some of their IoT solutions: smart cities (smart street lighting), smart energy meters (that reduced the customers' energy use), smart logistics (router optimization that cuts the fuel consumption) (Vodafone Sustainable Business Report 2019, 2019).

The product and service development plans, property management and base stations must comply with the laws of the country where they are implemented. Moreover, the telecommunication companies must report their sustainability actions annually, to provide an image to government authorities. PCF defined the process as government and industry relationships management and legal and ethical issues management. Telecommunication companies can create a strategy to operate an a responsible way to ensure: supply chain sustainability (their providers are operating taking into account their environmental footprint), human resources safety (their employees respect the safety practices defined in the EHS program) and anti-corruption polices (their employees do not bribe or take bribe by the government or any other bodies). Vodafone Group Plc has developed supply chain integrity programs, anti-bribery campaigns, the Code of Conduct training for employees (Vodafone Sustainable Business Report 2019, 2019).

The next table outlines the main business processes contributing towards the environment footprint, their linkage with the causes identified in the previous section using Ishikawa method and the proposed solutions, some of them already implemented by Vodafone Group Plc.

Table 7. Solutions for creating sustainable business processes

\begin{tabular}{|c|c|c|}
\hline Business process & Key solutions & $\begin{array}{l}\text { Ishikawa } \\
\text { causes }\end{array}$ \\
\hline $\begin{array}{l}\text { Manage environmental, health and safety } \\
\text { (EHS) }\end{array}$ & Development of an EHS program & $\begin{array}{l}\text { Man, } \\
\text { method }\end{array}$ \\
\hline $\begin{array}{l}\text { Evaluate the impact of operations on the } \\
\text { environment }\end{array}$ & $\begin{array}{l}\text { Development of a sustainable } \\
\text { development strategy }\end{array}$ & $\begin{array}{l}\text { Man, } \\
\text { method }\end{array}$ \\
\hline $\begin{array}{l}\text { Develop property strategy and long-term } \\
\text { vision }\end{array}$ & $\begin{array}{l}\text { Development of a long-term property } \\
\text { management taking into account } \\
\text { environmental factors (office } \\
\text { location, "green office") }\end{array}$ & $\begin{array}{l}\text { Man, } \\
\text { method, } \\
\text { mother } \\
\text { nature }\end{array}$ \\
\hline Engage the employees & $\begin{array}{l}\text { Development of a program to inform } \\
\text { and engage employees into } \\
\text { environmental activities (newsletters, } \\
\text { quizzes, team-building activities) }\end{array}$ & $\begin{array}{l}\text { Man, } \\
\text { method }\end{array}$ \\
\hline Develop sustainable products and services & $\begin{array}{l}\text { Development of IoT solutions (smart } \\
\text { cities, meters, logistics) }\end{array}$ & $\begin{array}{l}\text { Man, } \\
\text { method, } \\
\text { machine }\end{array}$ \\
\hline Manage sustainable products and services & $\begin{array}{l}\text { Tracking the success of the IoT } \\
\text { solutions developed and proposing } \\
\text { improvements }\end{array}$ & $\begin{array}{l}\text { Man, } \\
\text { method, } \\
\text { machine }\end{array}$ \\
\hline $\begin{array}{l}\text { Manage government and industry } \\
\text { relationships }\end{array}$ & $\begin{array}{l}\text { Reporting the progress towards } \\
\text { sustainable development every year }\end{array}$ & $\begin{array}{l}\text { Man, } \\
\text { Method, } \\
\text { mother } \\
\text { nature }\end{array}$ \\
\hline Manage legal and ethical issues & $\begin{array}{l}\text { Development of plans to ensure } \\
\text { supply chain sustainability, human } \\
\text { resources safety, anti-corruption }\end{array}$ & $\begin{array}{l}\text { Man, } \\
\text { method, } \\
\text { mother }\end{array}$ \\
\hline
\end{tabular}


In conclusion, this current analysis shows that solutions can be implemented to reduce the environmental impact of a telecommunication companies by improving the identified business processes. Action in this field is required in order to create a sustainable business.

PICBE $\mid 212$

\section{Conclusion}

This paper is an enhancement to the sustainable development of telecommunication companies because it provides an insight on the causes of their environmental impact and key business processes that need to be improved. The pairwise comparison method under GRI environmental disclosures provided an insight on the status of the telecommunication companies analyzed with regards to their energy consumptions, greenhouse gas emissions and the amount of emissions reduced. The result was then the input for a cause-effect diagram, that emphasized they key causes of the telecommunication company's environmental footprint. Possible solutions have been identified and seen as business process improvements categorized using the APQC standard for the telecommunication industry.

This paper contains few limitations. The comparison does not take into account the amount of base stations, the number of operating countries and the data traffic across the network for each telecommunication company analyzed, it only analyzes the 2018 reports and there are only five GRI disclosures on which the comparative analysis has been performed. In the future, a deeper analysis can be performed to identify the exact activities on each business process that influences the environment so that telecommunication companies would know exactly which areas need to be improved.

\section{Acknowledgement}

This work has been funded by the European Social Fund from the Sectoral Operational Programme Human Capital 2014-2020, through the Financial Agreement with the title "Scholarships for entrepreneurial education among doctoral students and postdoctoral researchers (Be Antreprenor!)", Contract no. 51680/09.07.2019 - SMIS code: 124539.

\section{References}

About GRI. (2017). Retrieved December 24, 2019, from https://www.globalreporting.org/Information/about-gri/Pages/default.aspx.

About the Sustainable Development Goals - United Nations Sustainable Development. (2015). Retrieved December 24, 2019, from https://www.un.org/sustainabledevelopment/sustainable-development-goals/.

CSR Orange Environmental 2018. (2018). Retrieved December 24, 2019, from https://csrdatas.orange.com/downloads/2018-CSR_Orange-environmental-en.pdf.

Deutsche Telekom Corporate Responsibility Report 2018. (2018). Retrieved December 24, 2019, from https://www.crreport.telekom.com/site19/sites/default/files/pdf/cr_en_2018_dt_final.pdf.

Domazet, I., Zubovic, J., \& Lazic, M. (2018). Driving factors of Serbian competitiveness: Digital economy and ICT. Strategic Management, 23(2), 20-28. 
GRI 302: ENERGY 2016 - Global Reporting Initiative. (2016). Retrieved December 24, 2019 , from https://www.globalreporting.org/standards/media/1009/gri-302-energy-2016.pdf.

GRI 305: EMISSIONS 2016 - Global Reporting Initiative. (2016). Retrieved December 24, 2019, from https://www.globalreporting.org/standards/media/1012/gri-305-emissions-2016.pdf.

Ikebe, H., Yamashita, N., \& Nishii, R. (2007). Green energy for telecommunications. INTELEC 07 - 29th International Telecommunications Energy Conference. doi: PICBE|213 $10.1109 /$ intlec.2007.4448882

Luca, L. (2016). A new model of Ishikawa diagram for quality assessment. IOP Conference Series: Materials Science and Engineering, 161. doi: 10.1088/1757-899x/161/1/012099

Non-financial reporting. (2019). Retrieved December 24, 2019, from https://ec.europa.eu/info/business-economy-euro/company-reporting-andauditing/company-reporting/non-financial-reporting_en.

Paunescu, C., Popescu, M.C., \& Blid, I. (2018). Business impact analysis for business continuity: Evidence from Romanian entreprises on critical functions. Management \& Marketing. Challenges for the Knowledge Society, 13(3), 1035-1050.

Rezaee, Z., \& Fogarty, T. (2019). Business sustainability, corporate governance, and organizational ethics. Hoboken, NJ: John Wiley and Sons, Inc.

Sivarajan S., Manikandan S., Rajeshkumar T., Ranadheer Reddy R. (2019). Recent Analysis of Green Energy Technology (GET) for Telecom Applications. International Journal of Recent Technology and Engineering Regular Issue, 8(4), 1326-1332. doi: 10.35940/ijrte.d7155.118419

Sutherland, E. (2016). Corporate social responsibility: the case of the telecommunications sector. Info, 18(5), 24-44. doi: 10.1108/info-05-2016-0022

Telecommunications Process Classification Framework. (2017). Retrieved December 24, 2019, from http://ldmc.com.br/wp-content/uploads/2017/03/PCF-Telecom-Ver_5.0.2.pdf.

The Method of Pairwise Comparisons. (2019). Retrieved December 24, 2019, from http://jlmartin.faculty.ku.edu/ jlmartin/courses/math105-F11/Lectures/chapter1-part4.pdf

Vodafone IoT. (2017). Retrieved December 24, 2019, from https://iot.vodafone.ro/serviciu-nbiot.php.

Vodafone Sustainable Business Report 2018. (2018). Retrieved December 24, 2019, from https://www.vodafone.com/content/dam/vodcom/sustainability/pdfs/sustainablebusiness2 018.pdf.

Vodafone Sustainable Business Report 2019. (2019). Retrieved December 24, 2019, from https://www.vodafone.com/content/dam/vodcom/sustainability/pdfs/sustainablebusiness2 019.pdf. 